Proc. NIPR Symp. Antarct. Geosci., 2, 169, 1988

\title{
EARTHQUAKE SWARMS ON MOUNT EREBUS, ANTARCTICA (ABSTRACT)
}

\author{
Katsumi MuraKami ${ }^{1}$ and Katsutada Kaminuma ${ }^{2}$ \\ ${ }^{1}$ Department of Physics, Faculty of Science, Tokai University, \\ 1117, Kitakaname, Hiratsuka 259-12 \\ ${ }^{2}$ National Institute of Polar Research, \\ 9-10, Kaga 1-chome, Itabashi-ku, Tokyo 173
}

Mount Erebus $\left(77^{\circ} 30^{\prime} \mathrm{S}, 167^{\circ} 09^{\prime} \mathrm{E}, 3794 \mathrm{~m}\right)$ is the only active volcano in Antarctica at present. The most notable featuie of the volcano is the existence of the convecting lava lake at the summit inner crater for more than ten years. Seven seismic explosion experiments at four different shot points were made on Mount Erebus in December 1984.

The average numbers of earthquakes per day which occurred around Mount Erebus in 1982, 1983, and January-August 1984 are 64, 134 and 146 events, and the numbers of earthquake swarms with more than 250 events per $24 \mathrm{~h}$ are 3,7 and 6 events respectively. A new volcanic eruptive activity began on 13 September 1984 and continued until December.

After the activity, the average numbers of earthquakes per day in 1985 and 1986 are 23 and 17 events, and the numbers of earthquake swarms are only one (85-A) and two (86-A, 86-B) events respectively.

The earthquake swarm activities of 85-A, 86-A and 86-B are as follows: 1) The durations of the activities are 66, 24 and $59 \mathrm{~h}$. 2) The total numbers of earthquakes are 2315,357 and 689 events. 3) Only seven earthquakes of 86-A and 86-B were determined to be located in the area beneath Mount Erebus, and the other earthquakes could not be located because the number of the stations is not enough for determining the earthquake locations.

Both the activity durations and the total number of earthquakes of the three earthquake swarms are smaller than those of the swarms which occurred before the September 1984 activity.

(Received May 6, 1988) 